\title{
Lexical and Semantics Literatures and Their Trends
}

\author{
Mohana Dass Ramasamy \& Devi Vadiveloo \\ Department of Indian Studies \\ University of Malaya
}

\section{Introduction}

It needless to elaborate in detail how words are formed. Creator's imagination that working along with his imagination give birth to new word formation whenever there is a need and necessity. The process of making or coining the new term, sometime easy and sometime not. By adding an affix or suffix to a root word, an intended word could be formed to fill the blank of missing message delivery. The only criteria of succession is it has to be the best term that could represent the abstract mental message or image borne in the mind. The ability to learn one's mother language as a unique faculty, as a special innate mental module.

The field of study known as lexical and lexical semantic have been established well in the literature, but they were less studied in the Tamil background. This study, therefore, aimed at giving an impressive look at the existing literatures on these fields, and possibly arguing for how they could be matched in the Tamil.

\section{Word Formation Literatures}

Word has different connection with various academic fields in this world. However, strong interconnection between word and linguistic have created an academic discipline alone, known as 'lexical' today. Lexical has different perspective from each discipline in academic world [Palmer (1981), Trask (1993), Crystal (1997)]. Morphology is study of lexical structure and semantics is the study of lexical meaning. Lexical participation in every field played a vital role to create great success in academic today.

Lexical Semantics also garnered extensive interest of the scholarly world. Since lexical semantics defined as study of word meaning, Lexical semanticists are interested in what words mean, why they mean so, what they mean, how they are represented in speakers' minds and how they are used in text and discourse(CaritaParadis 2013: 1). Lexical semantics also provides the foundation for various fields of applied research, such as research in language acquisition and learning (Robinson \& Ellis, 2008, Gullberg \& Indefrey, 2010, Pütz \& Sicola, 2010), with computational linguistics (Pustejovsky, 1995, Asher \& Lascarides, 2003) and with lexicography - the art and science of dictionary-making (Béjoint, 2010)(CaritaParadis 2013: 2).

Richard \& Platts (1993) of the opinion that lexical is a smallest unit in the meaning, system of a language. Trask (1993) and Crystal (1997) describes lexical as a smallest unit in a language; coveys abstract and constant meaning (Indirawati 1995: 12). They elaborated that word represents human's mind or idea is the main concept in communication. Our fore fathers were also have given concern on this the need for words to convey their idea within their family group and outsider. In this context, words played vital role as tool of communication in their life. At early stage, they were just focused in naming things whatever they see. After that, with limited vocabulary list, they started to link two or more than two words to name new captures of their eyes. This clearly proven by our vocabulary list entered in every language until today. This allows us to scrutinize the meaning of the lexical in depth.

Carita Paridas claims that (2013: 3) the relationship between words and meaning garned interest in Western literature the Aristotle's time. Nevertheless, lexical semantics evolved as research discipline in the $19^{\text {th }}$ century. Earlier, it was named as lexical semantics but it had a historical-philological orientation, and, thence it was mainly concerned with etymology and the classification of how meanings of words change over time (CaritaParadis 2013: 3). It is important to note that word meanings in the early days of lexical semantics were regarded as mental entities; they were thoughts, and change of meaning over time was the results of psychological processes, argued Carita (CaritaParadis 2013: 4). As a reaction to the psychological conception of lexical meaning in the historical-philological tradition, new ideas were brought to forefront in the 20th century by 
structuralist movement, associated with Ferdinand de Saussure's work (1959)(CaritaParadis 2013: 5). There are four major theoretical currents that shaped the development of lexical semantics: prestructuralist semantics, structuralist and neo-structuralist semantics, generativist and neo-generativist semantics, and cognitive semantics (DirkGeeraerts 2010: 1).

Pre-structuralist semantics exist roughly between 1870 and 1930. Research into word meaning establishes itself as a distinct sub-discipline of the new science of linguistics by scholars such as Bréal and many others, like Paul (1880), Darmesteter (1887), Nyrop (1913), Carnoy (1927) and Stern (1931). This theory mainly described lexical meanings as psychological entities, especially as thought and idea. The meaning change started to result from psychological process, says the appproach. This theory approach lexical meaning as a cognitive capacity of the human mind, they claimed.

Next in the line was structuralist and neostructuralist semantics. This theory was contributed by Trier (1931) through monograph. Weisgerber (1927) created first theoretical and methodological exposé of the new approach (inspired by De Saussure). He criticizes prestructuralist historical semantics precisely on the three characteristic points as below:

(a) Study of meaning should not be atomistic but should be concerned with structure of word

(b) It should be synchronic instead of diachronic

(c) Study of linguistic meaning should proceed in an autonomously linguistic way

Third major theory is known as generativist and neo-generativist introduced by Katz and Fodor (1963) in second half of the 1960s and the 1970s. Katzian (1981) was inspired by Chomskyanism (1986) and then he developed himself this theory by associating with Fodor. Katzian semantics brought together the three types of semantic relations that could lie at the basis of structuralist semantic theories. Katz pointed out explicitly that Semantic Theory should be concerned with lexical relations such as synonymy, antonym, and hyponymy. The further development of lexical semantics was characterized by two tendencies. In each case, semantics moved away from the structuralist pole of the Katzian synthesis towards one of the other two poles. On the one hand, the demands of formalization diminished the structuralist influence in semantics in favour of logical approaches to meaning analysis. On the other hand, attempts to take the mentalist position of Katzian semantics seriously led to a straightforward psychological, cognitive orientation in semantic studies. For reasons to be explained, the former approach can be called 'neo-generativist' (DirkGeeraerts 2010: 4).

Pustejovsky (1995), however, gave a new impetus to the Katzian idea of a formalized semantic representation by basing it on a logical rather than a featural formalism in 1990s (DirkGeeraerts 2010: 5). He also developed the Katzian ideal of a formal semantic representation by introducing semantic flexibility and a logical formalism. Cognitive semantics method remained structural, in the sense that it is based on static relations between linguistic elements, rather than on actual psychological processes (DirkGeeraerts 2010: 5). Cognitive semantic theories are typically built on the argument that lexical meaning is conceptual. That is, the meaning of a lexeme is not reference to the entity or relation in the "real world" that the lexeme refers to, but to a concept in the mind based on experiences with that entity or relation. Hence, it became impossible to associate with lexical items involving experience like one that involved in the study.

\section{Semantics Literatures}

Semantics as domain by itself has been studies extensively. The semantic term was first handled by Breal (1978), and none other scholars or literatures come up with this concept before him. This term is closely connected to philosophy field before it was introduced by Breal. Since then many started to examine the relationship between linguistic expressions and the phenomena they refer to in the external world and this was named as philosophical semantics. This can be traced to as far back as Plato's and Aristotle's works. However, contemporary philosophical semantics can be traced to the works of the following authors; Rudolf Carnap (1891 - 1970), Alfred Tarski (Born 1902) and Charles Peirce (1839-1914). 
According to Peirce (1839-1914), philosophical semantics developed as Semiotics in America while with the influence of Saussure in France, the term 'Semiology' was used. Later on this term was introduced by a non-linguistic Alfred Korzybski as separate discipline in linguistic field and brought scientific approach using semantics. This approach was continued by Odgen and Richards. Since the world is dynamic, the study of semantics has not been left out. One of such areas that have remained dynamic among others is the concept of change in meaning. Semantics has been at the fore in the study of change in meaning. As early as 1933, Bloomfield observed a system of change in the meaning of words.

Semantics is divided into two, logical semantics and linguistic semantics. Logical semantics is mainly related to calculation field and linguistic semantic is a study about nature of a language. Linguistic semantic believes that there is a strong connection between meaning and communication. It is also known as scientific study in linguistic term because analysis or interpretation of a word apart from sound (phonology) and structure (morphology). Moreover, semantics also related with other fields in academic world, namely philosophy, sociology and anthropology, psychology, mass communication worldwide.

Semantics is associated with different issues related to meaning including naming, concept, sense and reference. Semantics is study of heart of the meaning in a vocabulary, and it is divided into four, namely transitional semantics, behavioural semantics, structural semantics and generative semantics. Transitional semantics main focus was on the nature of human language itself. Traditional semantics was also concerned with the relationship between form and meaning. Following Carnap (1927), Firth (1957) and Ayer (1936), the meaning of a word is actually what it refers to. This view has also been shared by Ogden and Richards (1933). There have also been later scholars - Grice (1957) and Katz (1972) who believed that the image of a word takes shape in the speaker's or hearer's mind. This view supported by reference, concepts, and truth conditions idea mostly. Behavioural semantics approach was created by Watson Bloomfield and Skinner. This approach denies the concepts of transitional semantics. Scholars' supports identical human behaviour is experiencing the senses are the major cause of knowledge. The external environment is perceived to be the major stimulus to all human utterances. The stimulus-response scenario is synonymous with the cause and effect connection in most natural situations. They also argued that that by reducing meaning to observable entities, language, as an aspect of human favour can lend itself to examination. They also argue that meaning is influenced by reinforcement. The theory stresses nurture rather than nature. Thus, the physical environment is perceived to contribute to meaning rather than the internal thought processes.

Last one in the list is named as generative semantics. According to Noam Chomsky (1966) (father of generative theory), knowledge of language is generated in the mind. A language user has a finite set of rules from which he can generate an infinite number of sentences. At the beginning of Chomsky's generative grammar, there was the assertion that syntax was autonomous and independent of semantics. It was only later in Aspects of the theory of Syntax (1965) that Chomsky pointed out that the semantic component specifies the rules necessary for the interpretation of deep structures. This observation enhanced the semantic representation of sentences. Deep structures specify the original meaning of sentences before the application of transformations.

Generative semantics theory is occupied with sentence meaning and interpretation. Interpretation here has been described in 'case theory' by Charles Fillmore, and further elaborated in Chomsky's 'case theory and thematic theory'. There has been four theory discussed in semantic field as mentioned above. Three theories, namely traditional semantics, behavioural semantics and structural semantics are theories which belong to lexical but generative semantics is only focused to sentence/syntax structure.

Morphology and Semantics Involvement

Language is understood as a product of general cognitive abilities (Chomsky 1986; Fodor 1983). This cognitive exercise is not only limited to an educated person. Along this, few external also might be noted as instrumental in word formation. The formed word could be studied from two or more 
perspectives. Among them Morphological perspectives and Semantics perspectives ought to be treat of important area of studies. Among them the Morphology is dealt first for giving a structure by adducing attachments (suffix, infix and prefix), and the Semantic follows, as it dealt with the meaning for the structure.

Lieberman (2009: 5) claims that structure of a word can be well define with help of morphology. Structure of a word can be well define with help of morphology. Same words which added with affixes are basically known as lexeme. On the other hand, a word is added with another word (different lexeme) is known as lemma. Morphology as a sub-discipline of linguistics was named for the first time in 1859 by the German linguist August Schleicher who used the term for the study of the form of words.

Morphology is a field which studies word from smaller unit of speech and internal structure of word creation. Morphology is widely used in two situation, new word formation and modification of existing words. Morphology is different from syntax because morphology research structures of word alone and syntax is all about research on words used in sentences. Even though morphology and syntax are interrelated in speech but adding affix (suffix) might differentiate both in research field (Lieber 2009: 75). Additional morphemes attached with bound morphemes is also known as affix. Affix is an additional part which sticks with stems (root word which carries basic meaning) where whole meaning will change in this process. This one can be divided in four sub-categories; prefix, suffix, infix, circumfix. Prefix is a morph with added before stem. Suffix is a morph which will appear after stem. Infix morph will appear within a word and this morph is very common in BorneoPhilippines languages. Lastly, circumfix is a morph where will appear before and after a stem (Lieber 2009: 75). This information can be clearly seen with help of words below.

\begin{tabular}{|l|l|l|}
\hline Affix types & Example Words & Description \\
\hline Affix & reread & Affix + stem \\
\hline Suffix & reading & stem + suffix \\
\hline Infix & kumilad (be red) & Stem + infix \\
\hline Circumfix & enlighten & circumfix + stem + circumfix \\
\hline
\end{tabular}

Bound morpheme can be divided in to two category, derivation and inflection. Derivational morphemes create new words which will change meaning and word class of the word. For example, the word 'happy' will become 'unhappy' when prefix added front of adjective mentioned. Both are adjective but meaning changed with arrival of prefix. Inflection morphemes are different from this situation. Inflection morphemes do not alter word's meaning or word class but by adding suffix will only give extra grammatical information to a word. There are only eight inflection morphemes in English language as listed below.

\begin{tabular}{|l|l|l|}
\hline Inflection morphemes & Example words & Grammatical information \\
\hline -s & She waits & Third person singular present \\
\hline -ed & She waited & Past tense \\
\hline -ing & She is waiting & Progressive \\
\hline -en & I had eaten & Past participle \\
\hline -s & Tables are broken & Plural \\
\hline -'s & Chair's leg is broken & Possessive \\
\hline -er & She was faster & Comparative \\
\hline -est & She was the fastest & Superlative \\
\hline
\end{tabular}

Word formation is also known as morphology process in linguistic field. Our ancestors at early stage created only root words for communication. Later on, they started to add on morphemes and changed internal structure of morphemes with minimum knowledge. Evolution in morphology created word formation alone as a study in linguistics branch. Word formation is a term universal term which is only plays within word in almost all language in this world. Word formation has few processes such 
as coinage, borrowing, calque, compound, blending, backformation, conversion, acronym, initialism, clipping and derivation.

Word formation has another important field besides morphology, named semantics. Semantics is a linguistics branch which involves in two other branches such as morphology and syntax. Morphology is on word formation and syntax is about combination of words in creating sentence. Both equally needs semantics as mediator to convey message in social structure. In ancient period, there were two different argument brought up by philosophers; meaning of a word came naturally by its own and born from humans thinking process. In Greece, philosophers attempt to explain meaning where, physical nature of the sounds of a name can tell us something. But second group of philosophers said that name given to an object is chosen randomly without any system required (arbitrary).

These two situation was debated by Socrates. In his point of view, he said that 'we must admit that both convention and usage contribute to the manifestation of what we have in mind when we speak'(DirkGeeraerts 2010: 56). Later on, this field was continued by Plato. He opened a new way to syntax semantics. He indicate that meaning can be seen has a whole in syntax semantics rather than individual words. Aristotle was the next major contributor in this field where he took next step on analyzing language in semantics particularly. In the field of semantics proper, he identified a level of language analysis - the lexical one - the main purpose of which was to study the meaning of words either in isolation or in syntactic constructions. He deepened the discussion of the polysemy, antonym, synonymy and homonym and developed a full-fledged theory of metaphor.

Later on, Ferdinand de Saussure discussed nature of linguistic sign by obtaining result from relationship between signifier - semainon - (i.e. the sound or graphic aspect of the word), the signified - semainomenon (i.e. the notion)(DirkGeeraerts 2010: 52). This is known as reference meaning theory. Until the 19th century almost everything that came to be known about meaning in languages was the result of philosophic speculation and logical reasoning. It was in the 19th century that semantics came into being as an independent branch of linguistics as a science in its own right. The German linguist Ch. C. Reisig was the first to formulate the object of study of the new science of meaning which he called semasiology. He conceived the new linguistic branch of study as a historical science studying the principles governing the evolution of meaning.

Towards the end of the century (1897), M. Bréal published an important book Essay de sémantique which was soon translated into English and found an immediate echo in France as well as in other countries of Europe(DirkGeeraerts 2010: 18). He was interested on identifying certain general laws governing these changes via few general logics such as extension of meaning, narrowing of meaning, and transfer of meaning. After this tradition, semantics was continued in a modernized way which addressed as lexicography. Meaning of a word divided into categories such as polysemy, synonym, homonym, and antonym. After Bréal, Lazar Saineanu published a remarkable book entitled Incercare asupra semasiologiei limbei romane. Studii istorice despre tranzitiunea sensurilor.

The 1921-1931 decade has a particular significance where it is marked by the publication of three important books: Jost Trier, Der Deutsche Wortschatz im Sinnbezink des Verstandes (1931), G. Stern, Meaning and Change of Meaning (1931) and C. K. Ogden and J. A. Richards: The Meaning of Meaning (1923). Jost Trier product influenced by Saussurean principle: lexicon is analyzed in a set of collection which means lexicon list will expend when one lexicon is merged with another field and it is an endless analysis(DirkGeeraerts 2010: 52). This field expend to another level by Malinowski, an anthropologist creation 'The Problem of Meaning in Primitive Languages'. Crisis of semantics happened during decades 1930-1950. During this crisis semantics fell out of linguistic field and merged with other scientific fields such as chemistry, biology, psychology, sociology and anthropology.

"Crisis" of semantics, actually referred to the crisis of this linguistic discipline only from a structuralist standpoint, more specifically from the point of view of American descriptivism. It was only in the last years of the sixties that the organized attacks of the modern linguistic schools of different orientations was launched upon the vast domain of linguistic meaning. Later on this field got 
attention from scholars, who researched particular language by absorbing ideas of Western scholars. Malay semantics description were contributed by scholars, namely Awang Had Salleh (1959) and Ismail Muhammad (1959). After that, semantic change in Malay language stated to focus by scholars, Zaiton (1977). Hilmi Hj. Ismail in 1977 followed meaning classification introduced by Leech (1973) to discuss seven types of meaning found in Malay language. Hashim bin Musa (1988) studied about impact of Malay's culture in Malay language. This aspect is noticeable in his book, 'Bahasa Melayu Sebagai Bingkai Pemikiran Masyarakat Melayu'. From culture the focus changed to semantic change in word formation process. Mashudi Kader (1933) wrote about this in his book, entitled 'Aspek Semantik dalam Pembentukan Kata dan Istilah Bahasa Melayu'. Syntax was given attention by Roksana (1996) through her book, 'Istilah dalam bidang Sintaksis dari sudut analisis Komponensial'. This trend has changed now because semantics draw attention in other aspects namely, loan words and relation between words in other fields such as media, engineering and so on. Present studies are more focusing on problems in meaning. As far as we concern, semantics journey will never end till vocabulary creation stops.

\section{Collocation in Literature}

Another specific branch in semantics is collocation. Collocation is also another important element involved in word formation. Meaning can be divided into two different variables; lexical semantics and compositional semantics. Lexical creation started when human open their mouth but semantics importance was given when they accumulate meaning with lexical created. Each lexical has its own meaning in a way speakers think to convey it to others. Meaning still would reveal even these words tied together as a whole to explain it. Words arrangement in this is only accepted not more than three words together because more than that might overlap with compositional semantics (sentence). This situation is called as 'collocation' in semantics field.

A collocation is placing words which stays often together and give one meaning as a whole. 'Collocations' are usually described as "sequences of lexical items often co-occur"(Cruse 1986: 40). The term collocation was first introduced by Firth, who considered that meaning by collocation is lexical meaning "at the syntagmatic level"(Firth 1957: 196). Collocation can be divide into two sections: syntagmatic (horizontal axis) and paradigmatic (vertical axis) relations. Vertical axis means one word is belongs to one set of lexical. Horizontal axis refers to a word's ability to combine with other words.

Example: Richard ate orange.

From the example above orange stands in vertical axis with other set of lexical (food) such as apple, sweet, bread, sandwich and so on. In horizontal axis the word 'orange' is related to words 'Richard' and 'ate' only. Firth introduced the term 'collocation' in presence paradigmatic (vertical axis) relation. He did not focus on syntagmatic level such as antonym or synonym. Syntagmatic relations between sentence constituents had been widely used by structural linguists (e.g. 'John ate the apple' is a 'Subject-Verb-Object' construction), but not in the study of lexical meaning. Up till now, studies on collocation have been insufficient in defining the concept of collocation in a more rigorous way.

The lexical composition is based on assumption that words receive their meaning from the words they co-occur with. Firth, known as 'father of collocation' defined collocation as 'mode of meaning'. He believed that meaning can be present in different ways such as orthographic level, phonological level, grammatical level, and collocation level (Firth 1957: 192). Firth highlights the "general rule" that every word entering a new context is a new word. Halliday (1966) and Sinclair (1966) took Firth's theory of meaning one step forward and stressed the importance of lexical collocations, i.e. collocations that consist of lexical items, in an integrated lexical theory. Sinclair claim that grammar and lexical inter-related between each other but Halliday discovered that lexical theory is complementary but not part of grammatical theory.

The Neo-Firthians also introduced a new set of linguistic terms related to the study of collocations. Node refers to root word which stands alone to produce one meaning only at one time. Span refers to 
words which co-occur together with node in lexical creation.Halliday is also interested in the collocation patterns that lexical items enter. For example, 'a strong argument' presents the same collocation pattern as 'the strength of his argument' and 'he argued strongly'. Since 'strong', 'strength', and 'strongly', are parts of the same collocation pattern, they are considered as word-forms of the same lexical item (Halliday 1966:151).

A theory of lexical meaning similar to the one outlined by Firth and the Neo-Firthians is suggested by Anthony (1975). Anthony did not involve in collocation directly but he proposed theory treats the lexical word as an empty form capable of bonds to different kinds of meaning (M.Anthony 1975: 22). He said that one words' meaning may change according to situation and this is known as lexical meaning. He also added that lexical change in grammar only can form lexical in different form and meaning will change accordingly. For example, the word 'mother' can refer to both noun and verb in a sentence. Collocation has also been identified by Halliday and Hasan as a form of lexical cohesion, and it has been defined as the "cohesive effect" of pairs of words which "depends not so much on any systematic semantic relationship as on their tendency to share the same lexical environment, to occur in Collocation with one another"(Hasan 1976: 286).

The main problem with lexical analysis has been identified as "the circularity of the definition of the basic unit of description, the lexical item"(Sinclair 1966: 412). That is, every item is described in terms of its environment which in its turn is defined in terms of the item. For example, one of the meanings of 'night' is its collocability (i.e. ability to collocate) with 'dark', and of 'dark', its collocation with 'night' (Firth 1957: 196). The above realization makes lexical statements look weaker and less precise than grammatical ones, which are based on a well-defined and explicit framework.

One of the good points of the lexical composition approach is that it drew attention to lexis and uncovered the insufficiency of grammatical analysis to account for the 'patterns' a word enters in, in the Hallidayan sense, and the collocatory idiosyncrasies of lexical items. The Neo-Firthians argue that grammar alone cannot describe what the lexical item is, therefore the lexical item "must be identified within Lexis, on the basis of collocation"(McIntosh 1961: 65). Sinclair and Halliday do not underestimate the importance of grammatical analysis; they rather highlight the significance of being able to make valid statements about lexis that do not disregard but complement grammar. In other words, the advocates of the lexical composition approach recommend that collocation patterns are best described and analyzed through lexical analysis, but they do admit that help from grammar is still needed.

\section{Word Formation Trends in Tamil and Western}

The following diagram (Tamil word formation) show the comprehensiveness of the literatures and the areas in which interest has been shown in in the western world. Likewise, diagram (Tamil word formation) shows the setting of word formation trend in Tamil.

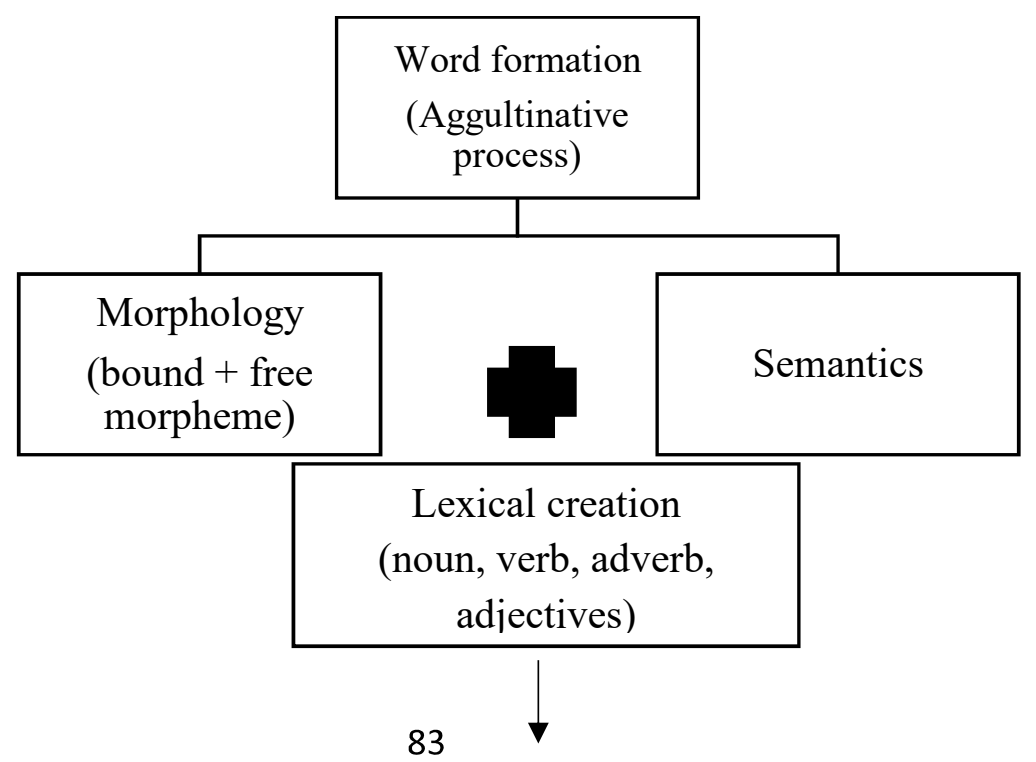




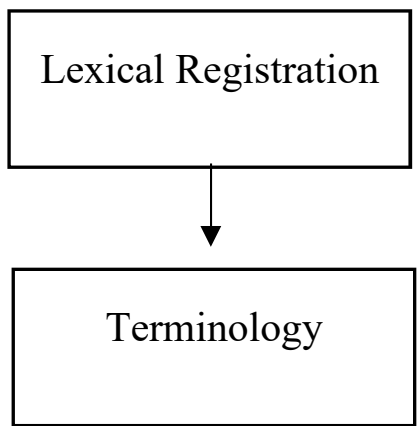

Figure 1 Word formation process in Tamil

Tamil is a flexible language in producing new words, by adopting 'agglutinative' process. In this way, the languages have shown how their lexicon was enriched. For this, these languages have heavily dependent on word formation and lexical creation, and the studies related to it were solely circled with studying the nature and offer semantic definition. In some cases, new trends were set and explored extensively under few topics, namely lexical semantic, collocation, and so on.

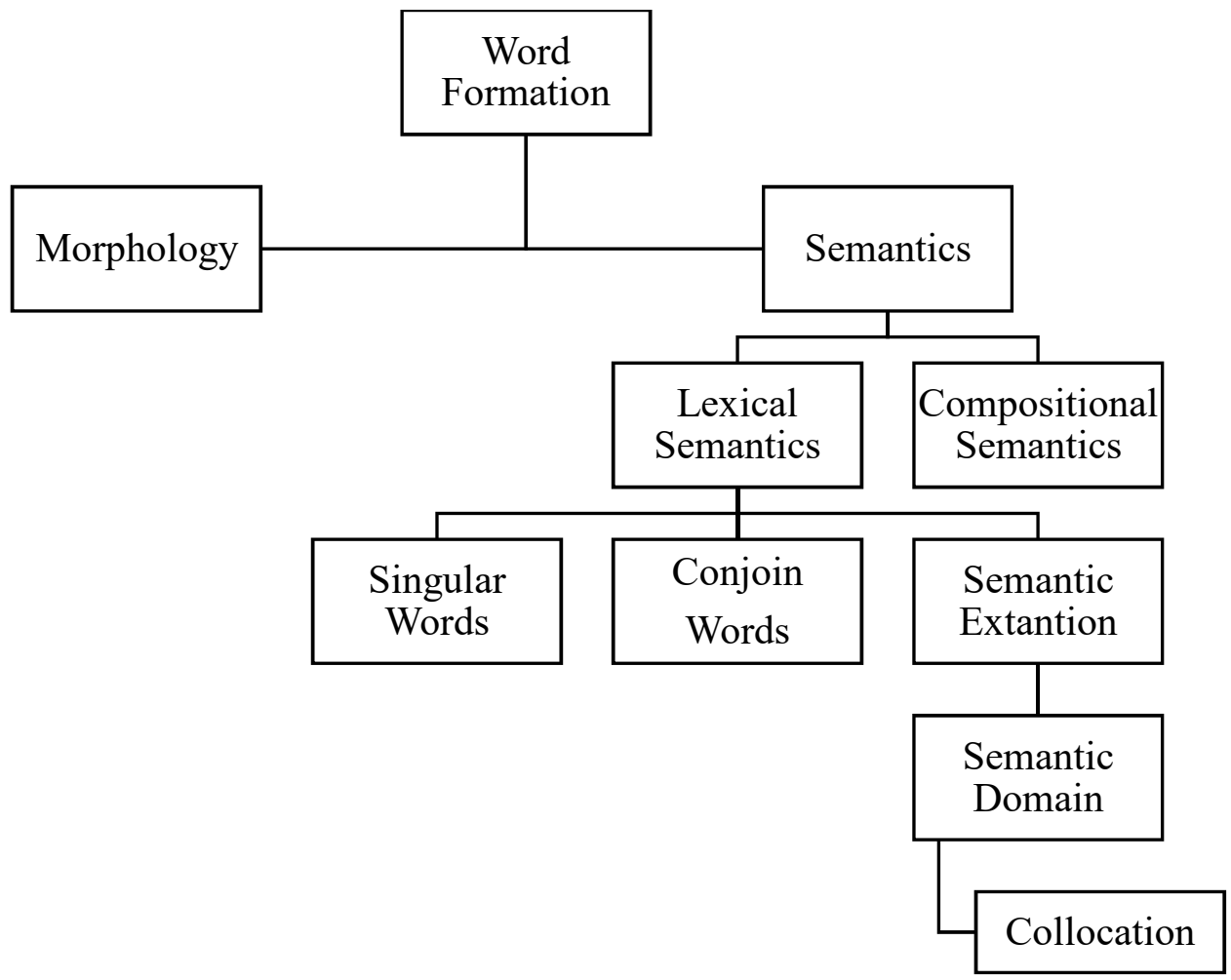

Figure 2 Word formation in Western

Word Formation starts as a thinking activity in human's mind. This aspect received attention of psychology and linguistic scholars as well since $19^{\text {th }}$ century [Paul (1880), Darmesteter (1887), Nyrop (1913), Carnoy (1927) and Stern (1931)]. Message from a human's mind compiled in a whole text at first. After that, linguistics narrowed word formation process into two major fields, morphology and semantics. Grammarians stressed word formation process by introducing morphology field in linguistics. Structures within a word expended vocabulary list in a language. When their meaning were addressed, the field became an important field as Semantics. It focused on two aspects, namely 
lexical and compositional semantics. Lexical is all about word and compositional is about sentences (syntax).

Lexical semantics divided into three dimensions: singular words, conjoin words and semantics extension. Singular words are from lexicon stored in human's mind since birth. Conjoin words are related to two different words when merged give a new meaning. To extend the meaning of words, new words were formed through semantic domain and collocation process. If a strict line drawn to prohibit word expansion lead to vocabulary creation, it might cause the language suffer depleting users, and eventually obsolete.

\section{Onomasiology}

There are handful of theory available to us when it comes to morphological study, but the number is limited when it comes to lexical based study. One of the theory that may shed a clear light to study the characteristics of the lexical items cultivated, developed and utilized maximally within occupational spectrum, especially of those involving people with less or none educational background strength might be Onomasiology Theory.

Onomasiology is a Greek word which refer to a study about expression of human's mind and word formation that tend to deal with rules and morphology in creation of a language. Onomasiological Theory was first introduced by series of writings published by scholars who have been working with Romance languages. They believed that formation of word and the method of naming them in a language is done based on human's intelligence involving thinking process. They also claimed that human's mind is capable of capturing and describing whatever is projected in their eye, and mind need to name them. This processing and naming exercise was first discussed as early as in $19^{\text {th }}$ century by Austrian linguist Adolf Zauner, scholar who was studying the etymology of Romance language. The theory later was noticed and popularized by Miloš Dokulil in 1962 (Stekauer $2005: 2$ ).

The OnoT received further scrutiny and elaboration through Dokulil (1962). He defined existence of a few categories and different levels revolving with various concepts within the theory. He claimed that an onomasiological term consists of two units, namely base and mark. For example, 'Blackberry', consist of two words, 'berry' which is an onomasiological base (common among other types of berries) and 'black', an onomasiological mark. Combination of these two would contribute to formation of new word with new meaning. In Dokulil's view, the basic types of onomasiological structure can be determined according to the categorical nature (substances, action, quality, and circumstance) as follows, (a) substance (policeman), (b) quality (blackberry), (c) action (teacher), and (d) concomitant circumstance (evening paper). These types of terms can stand for the multiplicity of semantic relations, including the Bearer of Quality (blackboard), and Agent (teacher)(Stekauer 2005: 2). Dokulil substance and Horecký's multilevel model of linguistic sign $(1983,1989)$ was absorbed in Pavol Štekauer's cognitive OnoT. Other onomasiological structure types are determined analogically, he claimed.

Along this there are few other ways in which linguist have paid attention in studying the nature of word-formation within selective contexts. Pavol Stekauer, (1996) added that the theory should give emphasis to semantic values, too, in the latter stage. Semantic expansion as a part of morphological aspects could not be undermined, as it also evolves with human mind. However, this aspect was recognized by only a few scholars. One of them is Pavol Štekauer. His focus was narrowed to relations between extra-linguistic reality (object to be named), a speech community (represented by a 'coiner'), and the word-formation component. Among the three components, the third component received huge attention among linguistics scholar but the other two were ignored by majority of scholars who ventured in lexical studies.

Pavol Štekauer's word-formation theory emphasis that naming units involve in the process starts with human, and stresses relations between linguistic and extra linguistic phenomenon. Naming an object closely connected to 'first contact' in a language, and only human who has wise language able to think and create name for an object. Strong language knowledge became an asset important asset in 
order to create new names in a field. Naming units involves substance such as human knowledge, human cognitive abilities, and experiences. Onomasiology is inter-related between human minds/cognitive and word formation.

\section{Conclusion}

When morphology enters in word formation automatically semantics changes will occur consequently. There is a clear vision in this word formation which follows the flow as first morphological process and next is semantic change. In between this there is a strong relation between two words while merging together to deliver one meaning. Humans mind is just like a scanner because it will scan object with similar qualities to name another new object they see every day. Onomasiological relation defines relation between two words merged together to deliver one meaning.

In this paper, we have offered an overview of word-formation literatures in the light of its subdomains, namely, Morphology, Lexical, Lexical-semantics, Collocation and Onmasiology. Along the way, we offered a comparative look between popular lexical fraction in Tamil and English, to show that both have almost similar components. Nevertheless, the studies in Tamil on lexical and its semantics confined within grammar framework, yet accrossed the limit to discover its true ability extensively. Only minimal number of studies are available. On the other hand, studies in English in line with the field under observation has been extensively studied. Our expectation is that the lucaritive field of study should be honoured with its deserved stake, proper investigations in Tamil.

\section{Bibliography}

CaritaParadis. (2013). Lexical Semantics. In C. C. A (Ed.), The Encyclopedia of Applied

Lingustics. United Kingdom: Wiley-Blackwell: Oxford.

Cruse, D. A. (1986). Lexical semantics (1st edition ed.): Press syndicate of the

University of Cambridge.

DirkGeeraerts. (2010). Theories of Lexical Semantics. United States: Oxford University Press.

Firth, J. R. (1957). Papers in linguistics, 1934-1951. London: Oxford University Press.

Hasan, H. (1976). Cohesion in English. London: Longman Group Limited.

Indirawati. (1995). Semantik Leksikal dalam Peribahasa Melayu. Universiti Malaya, Kuala Lumpur.

Lieber, R. (2009). Introduction Morphology (1st edition ed.). New York: Cambridge University Press.

M.Anthony, E. (1975). Towards a theory of lexical meaning. Singapore: Singapore University Press.

McIntosh, M. (1961). Patterns and ranges Language (pp. 325-337).

Sinclair, J. M. (1966). Beginning the study of lexis In Memory of J.R.Firth. London: Longman.

Stekauer, P. (2005). Onomasiological Approach to Word-Formation. In Stekauer-Lieber (Ed.), Handbook of Word-formation. Dordrecht: Springer. 